\title{
E-glass Coated Fibers in Novel Composite System for Constructional Applications
}

\author{
Shouresh Safaei \\ Ankara, Turkey
}

\begin{abstract}
Concrete is one of the most applicable materials in construction. But it needs to reinforce with several reinforcement materials especially high performance fibers such as glass fibers to improve its properties. Among glass fibers, E-glass fiber has lower price but degrade in alkaline cementitious matrix. In this investigation for prohibition of E-glass fibers degradation along with better adhesion of E-glass fibers to cementitious matrix a doubled layer composite coating has been used. The first layer is a polysiloxane which it's permeability to water is too low so prevent alkali attack on E-glass fiber. The second layer is polyvinyl acetate (PVAC) having polar groups of acetate, produce calcium acetate in cementitious matrix, which stick firmly to cement. PVAC in alkaline solution can produce polyvinyl alcohol (PVA) which is again sticky to cement. This composite coating applied on E-glass fibers and used to reinforce concrete. The durability of coated fibers was investigated by alkaline stability test and SEM images. Meanwhile for studying adhesion of fibers to concrete pull out characteristics of coated fibers been investigated and compared with bare E-glass reinforced concrete.
\end{abstract}

Keywords: polymer; composites; fibers; E-glass fibers; cement

\section{INTRODUCTION}

Cement-based materials are characterized by very good properties in compression but their brittle manner of failure under tensile or impact load was a limiting factor for their applicability range from the very beginnings [1,2]. Fiber reinforcement is a traditional and effective method how to improve the toughness and durability of cement based products $[3,4]$. The addition of a relatively small quantity of short random fibers to a cementitious matrix is known to improve the mechanical response of the resulting product, commonly known as a fiber reinforced cementitious composite (FRCC) [5]. The performance of FRCC depends on many factors, such as fiber material properties [6](e.g., fiber strength, stiffness, and Poisson's ratio), fiber geometry [7] (smooth, end hooked, crimped, twisted), fiber Volume content, matrix properties [8,9] (e.g., matrix strength [10], stiffness, Poisson's ratio), and interface properties [11] (adhesion, frictional, and mechanical bond) [12-13].glassfiber reinforced cement composites are frequently used as building materials in the world. Their enhanced tensile properties and durability make them suitable for thin constructional materials in both plain and complex shapes. Despite the glass fiber being considered as a reinforcement of cementitious materials for several decades, the limitation of structural applications still remains. Enhanced mainly by a high percentage of zirconia ( $\mathrm{ZrO} 2>15 \%$ byweight) content, the alkali resistant glass fiber (ARG) was designed to reinforce cementitious matrices which have been used in construction and civil engineering since the late 1960s. Previously, many attempts have been made to modify either matrix or fiber by adding fillers or by surface coatings of polymer and carbon layers. Both durability in alkali environment and economic considerations have restricted the commercial use of these materials. The multifunctional coating on the glass fiber surface is responsible to enable the manufacture and performance of the fibers, particularly the surface protection, abrasion resistance, retention of strength, and interphase formation of composites. In this study E-glass fiber have been coated by two coating layers that the inner layer was Poly(dimethylsiloxane-co-alkylmethylsiloxane) which it's permeability to water is too low so prevent alkali attack on Eglass fiber and the outer layer was polyvinyl acetate (PVAC) which having polar groups of acetate, produce calcium acetate in cementitious matrix, which stick firmly to cement. PVAC in alkaline solution can produce polyvinyl alcohol (PVA) which is again sticky to cement. This composite coating applied on E-glass fibers and used to reinforce concrete. The durability of coated fibers was investigated by alkaline stability test and SEM images. Meanwhile for studying adhesion of fibers to concrete pull out characteristics of coated fibers been investigated and compared with bare E-glass reinforced concrete.

\section{EXPERIMENTAL}

\subsection{Materials and Methods}

E-glass roving supplied from Diba Co., with 2400 dtex. Poly (dimethylsiloxane-co-alkylmethylsiloxane) that was used as inner layer was purchased from Aldrich Co. polyvinyl acetate (PVAC) was purchased from Aldrich Co and used as outer layer. The cement was Portland cement type II. Sand/cement ratio was 3 and water/cement ratio $(\mathrm{W} / \mathrm{C})=0.4$.

To remove any chemicals on the fibers surface, the fibers were dipped in a solution consist of 20 gr sodium dichromate and $35 \mathrm{~mm}$ water and 1 lit of concentrated sulfuric acid for 24 hours and then washed with aqueous solution of sodium bicarbonate then rinsed with deionized water. After this process the rinsed fibers were dried in vacuum oven for 4 hours. Concentrated solution of Poly (dimethyl siloxane-coalkyl methyl siloxane) in toluene was prepared and the fibers were dipped in it for 30 minutes the coated fibers were dried in vacuum oven at $80^{\circ} \mathrm{C}$ for $1 \mathrm{~h}$. The resultant fibers were dipped in a concentrated solution of PVAC in acetone. These fibers that have been coated by Poly (dimethylsiloxane-coalkylmethylsiloxane) and PVAC, were dried in a vacuum oven at $30^{\circ} \mathrm{C}$ for $1 \mathrm{~h}$. Then the coated fibers were added to concrete samples and durability and adhesion of them were investigated. For investigation alkaline durability of glass fibers, the alkaline bath was prepared according to ACI 440 (American Concrete Institute) and the durability of fibers was investigated after 28 days [12]. 


\section{RESULT AND DISCUSSION}

\subsection{Durability of fibers}

The load- displacement curves of raw and coated fibers in original form and after exposure to alkaline environment after 28 day were shown in Fig 1. As can be seen from Fig. 1 the coated fibers have higher mechanical properties than raw fiber which may be related to higher mechanical properties of polymers which is used for coating of fibers. Meanwhile coating of fibers with polymers could change brittle behavior of glass fibers to ductile form. E-glass fibers are sensitive to alkaline environment and loose their mechanical properties in cementitious matrix after a period of time. As can be seen the mechanical properties of raw E-glass fibers were decreased immediately after 28 days of immersion in alkaline environment. But coated fibers with polymers could remain their mechanical properties after this time.

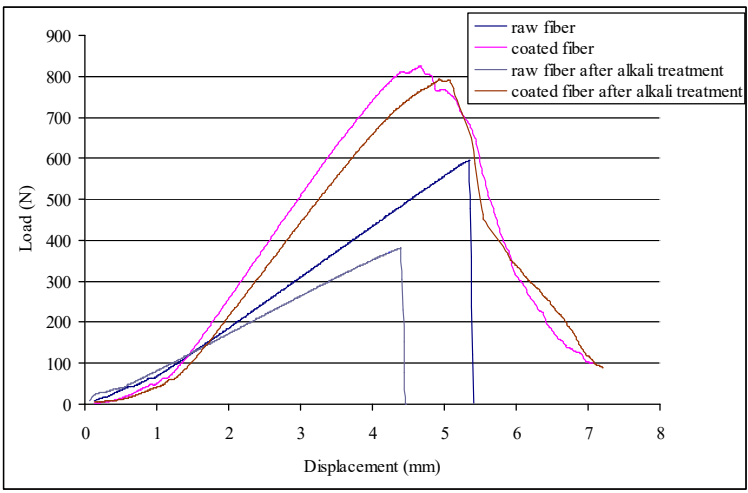

Figure 1. mechanical properties of E-glass fiber (a) raw fiber (b) coated fiber (c) raw fiber after immersion in alkaline solution (d) coated fiber after immersion in alkaline solution
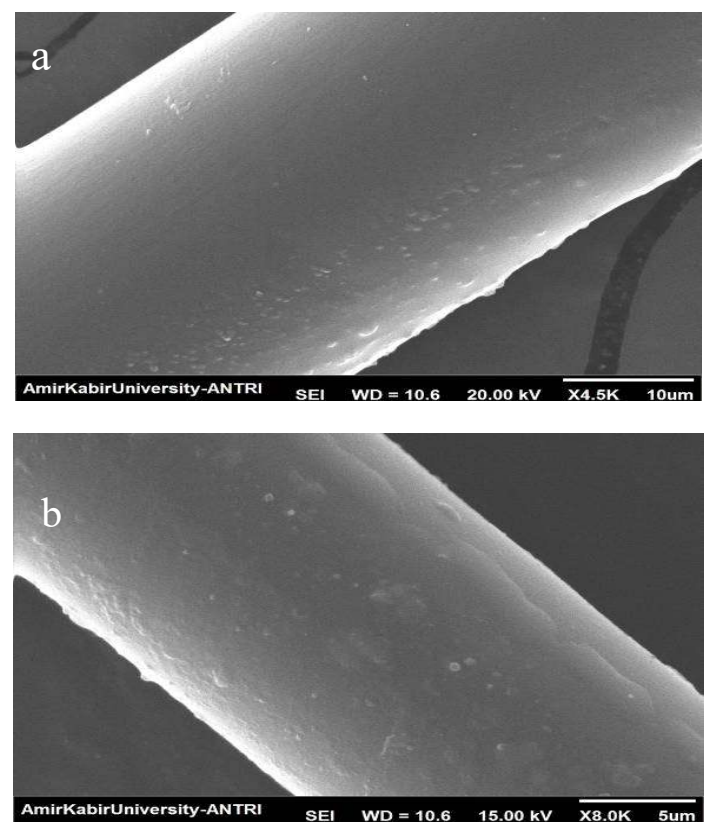

The results of SEM images were shown in Fig.2. As can be seen from this figure, the alkaline media influence the surface of E-glass fiber in comparison to raw fiber (Fig. $2 \mathrm{a}$ and b). But in coated fibers there were no recognizable change between coated fiber before and after immersion in alkaline solution. The holes on fiber surface of coated fibers before immersion in alkaline media could be related to coating process of fibers because after immersion of the coated roving in alkali, no changes in the holes were observed on fiber surface.

\subsection{Pull out behavior}

The pull out behavior of raw and coated glass fiber was illustrated in Fig.3. As can be seen there are no slippage in raw glass fiber but the maximum load of this fiber is much lower than original fiber because the degradation process.

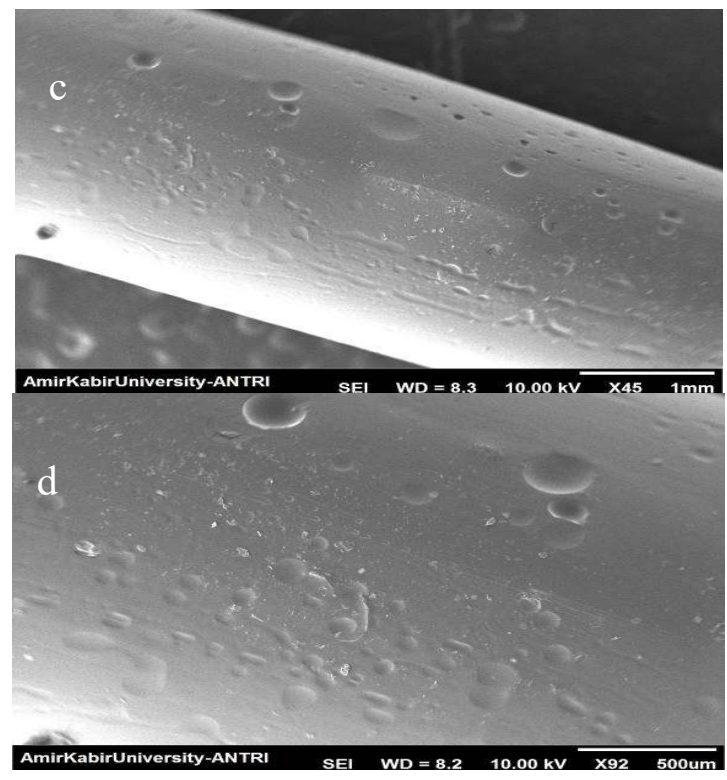

Figure 2. mechanical properties of E-glass fiber (a) raw fiber (b) coated fiber (c) raw fiber after immersion in alkaline solution (d) coated fiber after immersion in alkaline solution

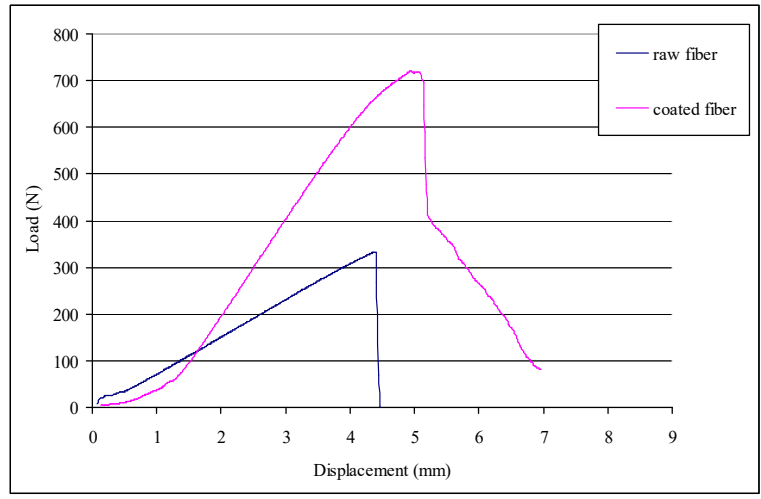

Fig.3 Pull out behavior of (a) raw glass fiber (b) coated fiber 


\section{CONCLUSION}

In this research E-glass fiber have been coated by two polymeric layers. The inner layer was Poly(dimethylsiloxaneco-alkylmethylsiloxane) with low permeability to water which prevent alkali attack on E-glass fiber and the outer layer was polyvinyl acetate (PVAC) which having polar groups of acetate, produce calcium acetate in cementitious matrix, which stick firmly to cement. PVAC in alkaline solution can produce polyvinyl alcohol (PVA) which is again sticky to cement. These polymeric coatings applied on E-glass fibers and used to reinforce concrete. The durability of coated fibers was investigated by alkaline stability test and SEM images. Meanwhile for studying adhesion of fibers to concrete pull out characteristics of coated fibers been investigated and compared with bare E-glass reinforced concrete. The results show that the mechanical properties of coated fiber and durability of these fibers are much more than raw E-glass fibers. Therefore pull out behavior of coated fibers after 28 days remaining in cementitious matrix is reasonable and proper.

\section{REFERENCES}

[1] Damircheli, D. and Bhatia, M., 2019. Solution Approaches and Sensitivity Analysis of Variational Inequalities. In AIAA Scitech 2019 Forum (p. 0977).

[2] Qiu, Q. and Kumosa, M., 1997. Corrosion of E-glass fibers in acidic environments. Composites Science and Technology, 57(5), pp.497-507.

[3] Sescu, A., Taoudi, L., Afsar, M.Z. and Thompson, D.S., 2016. Control of Gortler vortices by means of staggered surface streaks. In 46th AIAA Fluid Dynamics Conference (p. 3950).

[4] DAMIRCHELI, R., MIRZADEH, H., MORADI, H., GHAZIZADEH, Y. and JALALI, Z., 2014. ELECTROSPUN NANOFIBROUS SCAFFOLDS BASED ON CHITOSAN FOR SKIN TISSUE ENGINEERING.

[5] Stockhorst, H. and Brückner, R., 1982. Structure sensitive measurements on E-glass fibers. Journal of noncrystalline solids, 49(1-3), pp.471-484.

[6] JALALI, Z., HADDADI, A.V., Shabani, I., Soleimani, M., Shafiee, A. and Damircheli, R., 2014. Improving biocompatibility of the polyacrylonitlie nanofibrous scaffolds.

[7] Jones, R.L., 2006. Chemical Corrosion of E-Glass Fibers in Oxalic and Other Organic Acids. Journal of the American Ceramic Society, 89(1), pp.20-23.

[8] Ourang, A., Pilehvar, S., Mortezaei, M. and Damircheli, R., 2017. Effect of aluminum doped iron oxide nanoparticles on magnetic properties of the polyacrylonitrile nanofibers. Journal of Polymer Engineering, 37(2), pp.135-141.

[9] DAMIRCHELI, R., MIRZADEH, H., MORADI, H., GHAZIZADEH, Y. and JALALI, Z., 2014. ELECTROSPUN NANOFIBROUS SCAFFOLDS BASED ON ALGINATE FOR SKIN TISSUE ENGINEERING.

[10] Benmokrane, B., Wang, P., Ton-That, T.M., Rahman, H. and Robert, J.F., 2002. Durability of glass fiberreinforced polymer reinforcing bars in concrete environment. Journal of Composites for Construction, 6(3), pp.143-153.

[11] Karbhari, V.M., Murphy, K. and Zhang, S., 2002. Effect of concrete based alkali solutions on short-term durability of E-glass/vinylester composites. Journal of Composite materials, 36(17), pp.2101-2121.

[12] JALALI, Z., HADDADI, A.V., Shabani, I., Soleimani, M. and Damircheli, R., 2014. A novel method for producing gelatin nanofibers contains hydroxyapatite nanoparticles.

[13] Velpari, V., PPG Industries Ohio Inc, 2003. Use of Eglass fibers to reduce plastic shrinkage cracks in concrete. U.S. Patent 6,582,511. 